\title{
Obesity is Associated with Increased Prevalence of Glenohumeral Osteoarthritis and Arth roplasty
}

\author{
Kevin C. Wall
}

\begin{abstract}
A Master's Paper submitted to the faculty of the University of North Carolina at Chapel Hill in partial fulfillment of the requirements for the degree of Master of Public Health in the Public Health Leadership Program
\end{abstract}

\section{Chapel Hill}

2018 
Title: Obesity is Associated with Increased Prevalence of Glenohumeral Osteoarthritis and Arthroplasty

Authors: Kevin C. Wall, BA ${ }^{1,2}$, Cary S. Politzer, MD¹, Grant E. Garrigues, $\mathrm{MD}^{3}$

1. Duke University School of Medicine, Durham, NC

2. University of North Carolina Gillings School of Global Public Health, Chapel Hill, NC

3. Division of Sports Medicine and Shoulder Surgery, Department of Orthopaedic Surgery, Duke University Health System, Durham, NC

Manuscript word count: 2970 


\begin{abstract}
:
Introduction: It is known that there is an association between higher body mass index (BMI) and lower extremity osteoarthritis (OA), but the presence of this degenerative disease in the shoulder remains relatively unknown. Adipokines, cytokines at increased concentrations in higher body mass index (BMI) individuals play a role in cartilage degeneration providing a plausible link between BMI and glenohumeral OA. We examined the association between BMI and the prevalence of glenohumeral OA and arthroplasty.
\end{abstract}

Methods: This retrospective cohort study compared 596,874 age and gender matched patients across six BMI cohorts from a private payer database (Humana). The prevalence of glenohumeral OA was determined in each cohort, as was the standardized arthroplasty rates. Odds ratios were calculated for both OA and standardized arthroplasty rates by comparing the reference cohort, BMI < 19, cohort to the other five BMI cohorts.

Results: Individuals in the five cohorts above the BMI $<19$ level were all at increased odds of developing glenohumeral OA compared to those in the BMI < 19 cohort (OR range: 1.21 1.92). Those in the three cohorts above BMI 30 were also at increased odds of undergoing arthroplasty (OR range: 1.19 - 1.52) compared with the reference standard.

Conclusions: Patients with higher BMI are at increased odds of developing glenohumeral OA, despite the conventional belief that such an association is limited to hip and knee joints. Additionally, the previously unreported finding of an increased rate of arthroplasty performed on 
obese patients represents a novel source of a disproportionately high surgical burden among this segment of the population.

Abstract word count: 252 


\section{Introduction:}

Osteoarthritis (OA) and obesity are widely recognized as two integrally associated pathologies. The classic model of their relationship states that increasing body weight places a proportionally greater degree of mechanical stress on weight-bearing joints, leading to the development and progression of primary $\mathrm{OA}^{1}$. Increased prevalence of $\mathrm{OA}$ of the hip and knee in obese individuals is consistent with this theory ${ }^{2-5}$. Recent research into obesity, however, has demonstrated that excess adipose tissue exerts an additional influence beyond the forces its mass applies to the body’s susceptible joints. By a variety of mechanisms. obesity also induces a state of chronic, low-grade inflammation ${ }^{6}$ with evidence of multiple systemic proinflammatory factors ${ }^{7}$. Adipokines (adipose tissue-secreted cytokines) are one such factor that has recently been shown to contribute to the pathophysiology of OA affecting both cartilage loss ${ }^{8}$ and pain $^{9-}$

11. In an attempt to understand the relative importance of the mechanical effects of obesity versus the systemic inflammatory effects, we attempted to study a large joint classically described as “non-weight bearing”-the glenohumeral joint.

\section{Osteoarthritis:}

Osteoarthritis is the leading cause of disability among American adults, affecting $22.7 \%$ of the population ${ }^{12,13}$. As such, it costs approximately $\$ 80.8$ billion in direct medical costs, and $\$ 47$ billion in indirect costs such as lost productivity ${ }^{14}$. Although the exact pathogenesis of OA continues to evolve, a variety of risk factors have been identified that affect gross and histological changes to cartilage tissue. Patients at increased risk include females, the elderly, obese individuals, and those with genetic predispositions ${ }^{5,15}$. Among individuals with these risk factors, the typical composition of articular cartilage - type II collagen and proteoglycans - will 
begin to pathologically degrade. As a result, chondrocytes, the tissue's sole cell type, will cluster, undergo hypertrophy, and secrete enzymes that breakdown the extracellular matrix, ultimately destroying the cartilage. This process progresses and ultimately results in the morbidity of increasing pain and decreasing range of motion ${ }^{16}$.

The glenohumeral joint is a relatively uncommon location for OA and may have an prevalence as much as 300 times lower than the $45 \%$ prevalence that is routinely reported for knee $\mathrm{OA}^{17}$. While significantly rarer than hip, knee, and hand OA, glenohumeral OA nonetheless represents a significant burden of disease $\mathrm{e}^{3,5}$. First-line management for this disease is often defined by some combination of nonsteroidal anti-inflammatory drugs, activity modification, corticosteroid injections and physical therapy, all of which may improve pain and function to some degree ${ }^{18}$. However, given that these conservative, symptom-managing treatments do not modify the progression of the underlying disease, the decision to perform surgery is often made when the pain and loss of function have progressed to the point of warranting a change ${ }^{3}$.

Multiple operative approaches are used in treating glenohumeral OA that is refractory to nonoperative treatment. In the category of arthroplasty procedures for OA are hemiarthroplasty, total shoulder arthroplasty, and reverse total shoulder arthroplasty - each of which has its own short, mid and long-term success rates and complications. ${ }^{3}$

Obesity:

Obesity is a well-established concern in the United States with an estimated prevalence of $36.5 \%$ of all adults ${ }^{19}$ and an annual cost of $\$ 147$ billion in medical spending. This amounts to 
$42 \%$ more per capita medical spending than that which is spent on non-obese individuals ${ }^{20}$. The source of this increased spending is largely derived from obesity’s relationship to diabetes, dyslipidemia, atherosclerosis ${ }^{21}$ and the resultant increased risk of stroke and cardiovascular disease $e^{7}$.

The wide-ranging effects of obesity are, in part, secondary to the numerous, proinflammatory immunological changes that occur in adipose tissue of those with obesity ${ }^{21}$. For example, higher circulating levels of lipopolysaccharides and free fatty acids both result in macrophage infiltration of adipose tissue ${ }^{6,22}$. Accompanying these macrophages are neutrophils, mast cells, B- and some subsets of T-lymphocytes as eosinophil and Th2 cell counts decline ${ }^{7}$. Obesity also contributes to the relative underperfusion and subsequent hypoxia of adipose as the amount and metabolism of this tissue increases ${ }^{6,23}$. Thus, as the physiological equilibrium of immune cells in fat tissue is perturbed, the initially-local inflammation results in increased synthesis of proinflammatory cytokines, namely leptin, adiponectin, TNF- $\alpha$, IL-6, and monocyte chemoattract protein-1 (MCP1) 7,24,25, and the systemic inflammatory state is produced and perpetuated ${ }^{7}$. When these proteins are disseminated throughout the body, they exert their effects on the body’s tissues, adding an additional, chronic inflammatory stressor on joints not encountered by non-obese individuals.

\section{Obesity and Osteoarthritis:}

As two widely prevalent diseases, the interplay between obesity and OA has been well studied. In American adults who are normal or underweight, the prevalence of OA is approximately 16\%, which increases to $23 \%$ among overweight adults, and $31 \%$ for obese 
individuals ${ }^{15}$. In fact, the previously cited statistic of a $45 \%$ lifetime risk for developing symptomatic knee OA increases to $60.5 \%$ among obese individuals ${ }^{17}$. This relationship is further corroborated by studies demonstrating a decreased risk of symptomatic OA among patients who lose weight, and an increase among those who gain weight ${ }^{26}$.

As a known risk factor for OA, researchers have postulated how excess adipose tissue contributes to this degenerative pathology. Mechanical models, such as changes in joint biomechanics ${ }^{27}$ have prevailed historically, but the recent focus on adipokines helps to broaden the understanding of obesity's effects, particularly on non-weight-bearing joints where obesityinduced mechanical forces theoretically have less of an effect ${ }^{28-31}$.

Among the adipokine class of cytokines, leptin, adiponectin, resistin, and IL-6 have received the most attention. Both IL-6 and leptin have been associated with the loss of cartilage and the development of knee $\mathrm{OA}^{8,32,33}$, but this effect has been understudied in the glenohumeral joint. In a study of South Koreans over age 65, obesity was found to be significantly associated with spine and knee OA with odds ratios (OR) of 1.5 and 3.4 respectively. This same study also found an OR of 1.7 for shoulder OA that was not statistically significant; however, the study was underpowered to detect a difference for shoulder OA (only 36 subjects of 1,118- sampled had shoulder OA) ${ }^{34}$. In 2012, Gandhi, et al. wrote a letter to the editor in which they demonstrate that adipokines - primarily leptin - are present in shoulder synovial fluid in a group of patients with a mean BMI of $28.3 \mathrm{~kg} / \mathrm{m}^{2}$, however their study was limited by a cross-sectional design and a lack of a control group of normal weight individuals ${ }^{35}$. This letter was followed by an article in 2013 
in which they demonstrated that higher leptin and adiponectin levels in shoulder synovial fluid were associated with higher patient-reported pain $\operatorname{scores}^{28}$.

Our purpose is to define the prevalence of shoulder OA in obese and non-obese populations, as well as to understand the rate and type of shoulder arthroplasty procedures performed across BMI categories - to the best of our knowledge, the first such analysis on this topic. Despite the fact that the shoulder is a "non-weight bearing joint"28-31 and thus should not be as susceptible as the knee ${ }^{4}$ and hip ${ }^{2}$ to the increased mechanical forces secondary to obesity, we hypothesize that the obese state will still lead to an increased prevalence of shoulder OA, particularly bilateral OA, and a greater number of shoulder arthroplasties when compared with non-obese individuals.

\section{Methods:}

This retrospective review was conducted using the database of the private payer Humana from 2007-2016 quarter 3 (q3) and was accessed with the PearlDiver Technologies user interface (Warsaw, IN, USA). This database contains claims information from over 23.5 million patients with an orthopaedic diagnosis in that time period. This study was considered exempt from further review by our Institutional Review Board.

The database was queried for body mass index (BMI) using International Classification of Diseases, Ninth Revision, Clinical Modification (ICD-9) diagnosis codes for BMI under 19 $\mathrm{kg} / \mathrm{m}^{2}$ to BMI over $39 \mathrm{~kg} / \mathrm{m}^{2}$ in $5 \mathrm{~kg} / \mathrm{m}^{2}$ increments. ICD-10 codes were also used for 2015 quarter 4 (q4) to 2016q3 (Appendix). Cases were grouped by BMI (under 19, 20-24, 25-29, 30- 
34, 34-39, over 39). Since ICD-9 and ICD-10 both use integers to define BMI ranges, the customary threshold between underweight and normal BMI of $18.5 \mathrm{~kg} / \mathrm{m}^{2}$ is coded as BMI $<19$ and BMI 19-24, respectively. All cohorts were matched by age and gender using PearlDiver command language, resulting in six cohorts of 99,479 patients each with identical age and gender makeup. This preferentially selected for younger and female patients, especially among the lower-BMI cohorts. Charlson Comorbidity Index (CCI), a measure of 10-year predicted mortality, was also calculated for each matched group ${ }^{36}$.

The prevalence of arthritis in each BMI cohort was attained using ICD-9 and ICD-10 diagnosis codes for primary glenohumeral OA. To determine how many patients with shoulder OA underwent shoulder arthroplasty - reverse total shoulder arthroplasty (RTSA), hemiarthroplasty (HA), and total shoulder arthroplasty - in each BMI cohort, ICD-9 and ICD-10 procedure codes were used. Current Procedural Terminology (CPT) codes were not used because there is no code that identifies RTSA specifically. When comparing BMI cohorts for OA and arthroplasty incidence, odds ratios and 95\% confidence intervals were calculated with $\alpha=$ 0.05. The BMI < 19 cohort was used as the reference cohort in analysis to more comprehensively assess the spectrum of potentially increased risk of OA and arthroplasty across all BMI cohorts, including the normal, BMI 19-24 cohort. CCI scores were grouped into values of 0, 1, 2 and at least 3 and Pearson's Chi-Square was tested across all six BMI cohorts. Arthroplasty rates were calculated by dividing the number of shoulder arthroplasties performed in each BMI cohort by the number of patients in each respective cohort who have glenohumeral OA, thus standardizing the rates across cohorts and minimizing any potential effect that changes in OA rates may have on arthroplasty rates. 


\section{Results:}

Of the 2,748,702 patients with a BMI diagnosis code in the Humana database, 596,874 were able to be matched by age and gender into BMI cohorts so that each cohort had the same proportion of each age and gender group. Collectively, these age- and gender-matched BMI cohorts make up the primary cohort of this study. Of the primary cohort, 27,803 (4.66\%) had a diagnosis of primary glenohumeral OA. The BMI cohorts had statistically different CCI scores, $(P<0.001)$ indicating each BMI cohort has a different average health status and 10-year estimated mortality (Table 1).

Since the matched BMI < 19 group had the lowest proportion of shoulder OA, the prevalence in all other groups was compared to this cohort (Table 1). Glenohumeral OA was present in $3.76 \%$ of patients in the BMI $19-24$ cohort versus $3.14 \%$ of patients in the BMI $<19$ cohort (odds ratio [OR], 1.21; 95\% confidence interval [CI], 1.15-1.27; $P<0.001$ ), 4.40\% of patients in the BMI 25-29 cohort (OR, 1.42; CI, 1.36-1.49; $P<0.001)$, 5.11\% of patients in the BMI 30-34 cohort, (OR, 1.66; CI, 1.59-1.74; $P<0.001$ ), 5.68\% of patients in the BMI 35-39 cohort (OR, 1.86; CI, 1.78-1.94; $P<0.001)$, and 5.86\% of patients in the BMI $>39$ cohort (OR, 1.92; CI, 1.84-2.01; $P<0.001)$.

Of patients with glenohumeral OA, the standardized rate of shoulder arthroplasty of the BMI $<19$ cohort $(7.02 \%)$ was not different from the BMI $19-24$ cohort's rate of $6.84 \%(P=$ 0.787) or the BMI 25-29 cohort's rate of 7.51\% $(P=0.430)$. However, the cohorts with greater BMI did have higher standardized rates of arthroplasty; $8.23 \%$ of patients in the BMI 30-34 
cohort underwent shoulder arthroplasty, significantly higher than in the BMI $<19$ cohort (OR, 1.19; CI, 1.00-1.41; $P=0.048$ ). Similarly, the $10.45 \%$ standardized rate in the BMI $35-39$ cohort demonstrated a statistically significant OR of 1.54 (CI, 1.31-1.82; $P<0.001$ ) when compared to the reference cohort, as did the standardized rate of the BMI > 39 cohort, 10.28\% (OR, 1.52; CI, 1.29-1.78; $P<0.001)$.

\section{Discussion:}

We hypothesized that the prevalence of glenohumeral OA and rate of shoulder arthroplasty would increase as patient BMI increased. To test this hypothesis, we mined nine years of data from a large insurance database for patients with a recorded BMI and filtered six cohorts of these individuals by a diagnosis of glenohumeral OA and subsequent arthroplasty. The overall prevalence of glenohumeral OA was $4.66 \%$. There was a small but significant and progressive increase in OA prevalence with increased BMI.

The fact that there exists an association between obesity and OA in what has customarily been described as a "non-weight-bearing joint”28-31 requires considering mechanisms beyond the traditional mechanical forces model of OA, especially that glenohumeral OA is more the result of the chronic, systemic inflammatory state of obesity than the mechanical environment of the joint. As adipokines rise with accumulation of additional adipose tissue, leptin, which has been discovered in glenohumeral synovial fluid ${ }^{28,37}$, may be mediating increased cartilage destruction $10,32,38,39$. 
Leptin has proven destructive effects on cartilage and local differences in leptin concentration suggest that all joints are not equally affected. Leptin simultaneously slows chondrocyte proliferation while stimulating the same cells to increase synthesis of the proinflammatory molecules IL-1 $\beta$, MMP-9 and MMP- $13^{38}$. While increased leptin levels have been observed in the infrapatellar fat pad of obese individuals ${ }^{37,40,41}$, and thus posited as a mechanism for OA development in the adjacent knee joint, it is unclear whether the adipose tissue surrounding the shoulder behaves similarly. As our data show, however, even in the absence of this fat pad that theoretically influences the knee joint, the shoulder will nonetheless suffer higher OA rates in individuals with more overall adipose tissue.

In addition, we found that the increased standardized rates of shoulder arthroplasty among patients with glenohumeral OA was greater in patients with higher BMI levels. All BMI cohorts over $30 \mathrm{~kg} / \mathrm{m}^{2}$ demonstrated significantly greater odds of having this procedure than our referent (BMI < 19). To attempt to contextualize this finding, we note the reason why the decision to progress to operative management is often made: failure of conservative therapy, often manifesting as refractory or increased pain.

One plausible explanation for why higher BMI patients may experience this worsened pain is the concurrent upregulation of central NMDA receptors and enhanced excitation of the same pathway in the presence of leptin ${ }^{11}$. It is possible that at increased plasma leptin levels, as seen in the obese patient ${ }^{32}$, the central nervous system of the higher BMI patient is modulated in such a fashion, thus predisposing the patient to the resultant sensitivity to neuropathic pain. As highlighted by Gandhi et al, shoulder OA pain may present as constant, dull and aching pain or 
as what is presumed to be neuropathic pain, characterized as fleeting, but both physically and emotionally intense ${ }^{9,28}$. Gandhi and his colleagues further noted that synovial fluid leptin concentrations were predictive of scores on the short form of the McGill Pain Questionnaire (a patient-reported questionnaire for evaluating pain intensity, quality and behavior), further reinforcing the leptin-pain hypothesis. Thus, the increased arthroplasty rates among the higher BMI cohorts may be a function of this modified pain pathway and potentially may have significant therapeutic implications.

Evidence exists for treating OA pain as, at least in part, neuropathically mediated, with serotonin-norepinephrine reuptake inhibitors, primarily ${ }^{42-45}$, but also venlafaxine ${ }^{46}$, both showing effect. Indeed, the strength of evidence for duloxetine's pain-reducing effect was sufficient enough that it is now FDA-approved for this indication ${ }^{47}$. Similarly, two other neuromodulators in gabapentin ${ }^{48}$ and lacosamide ${ }^{49,50}$ have been successfully used to treat the pain of OA. Despite the evidence that treating OA pain centrally has potential, we are unaware of any studies that have focused on the effect of these medications in the obese population, where their effect may be more poignant given the potential sensitization to this type of pain in this group.

The ultimate potential benefit of this finding is the opportunity to prolong the time, or considerably reduce the need, to perform arthroplasty in this segment of the population that experience glenohumeral OA at this increased rate. If the exact mechanisms by which obesity gives rise to these higher operative rates can be elucidated, then there is potential for adding a new line of medical management to the standard of care in overweight and obese patients with OA. In the same vein, recommending weight loss among the obese OA patient population as a 
specific means of treating their OA, even glenohumeral OA, may also prove to beneficial. Future studies that research the effect of adding anticonvulsant or antidepressant drugs to the therapeutic regimen prescribed to the obese OA patient would serve well to answer the question of this approach’s efficacy.

This study was not without limitations. By accessing an existing database of insurance claims through PearlDiver, we were limited to only data based on ICD-9 and ICD-10 codes, hindering our ability to analyze arthroplasty type more specifically or chart reviewing for additional information. The difference in CCI scores across BMI cohorts also presents a source of potential confounding. However, the increase seen in these scores at the extremes of the BMI ranges is not entirely unexpected, as underweight and obese individuals generally tend to be more ill. Given that our cohorts were already age and gender matched, we controlled for the main risk factors that predispose individuals to OA, making it unlikely that any other comorbidity captured by the CCI scores would serve as a significant mediator of the BMI effect we found on OA rates. That said, residual confounding due to various clinical and demographic variables is still a potential bias. Another limitation was our inability to dictate the nature of the data captured for this database - for example, the lack of information on prescribed medications - makes it impossible for us to determine the effect that anti-neuropathic pain medication may have on arthroplasty rates. Future research that examines this effect may serve well to not only help patients with glenohumeral OA, but any obese or overweight OA patient.

Despite these limitations, this study contributes to a better understanding of the adverse effects that obesity has on the prevalence of glenohumeral OA. Additionally, the previously 
unreported finding of an increased rate of glenohumeral arthroplasty performed on overweight and obese patients represents a novel source of a disproportionately high surgical burden among this segment of the population. 


\section{Acknowledgments:}

The authors wish to thank Donald T. Kirkendall, ELS, for his assistance in editing and preparing this manuscript. 


\section{References}

1. Neogi T. The epidemiology and impact of pain in osteoarthritis. Osteoarthritis Cartilage 2013;21:1145-53. doi:10.1016/j.joca.2013.03.018.

2. Bourne R, Mukhi S, Zhu N, Keresteci M, Marin M. Role of obesity on the risk for total hip or knee arthroplasty. Clin Orthop Relat Res 2007;465:185-8.

doi:10.1097/BLO.0b013e3181576035.

3. Chillemi C, Franceschini V. Shoulder osteoarthritis. Arthritis 2013;2013:370231-. doi:10.1155/2013/370231.

4. Grotle M, Hagen KB, Natvig B, Dahl FA, Kvien TK. Obesity and osteoarthritis in knee, hip and/or hand: an epidemiological study in the general population with 10 years follow-up. BMC Musculoskelet Disord 2008;9:132-. doi:10.1186/1471-2474-9-132.

5. Litwic A, Edwards MH, Dennison EM, Cooper C. Epidemiology and burden of osteoarthritis. Br Med Bull 2013;105:185-99. doi:10.1093/bmb/lds038.

6. Saltiel AR, Olefsky JM. Inflammatory mechanisms linking obesity and metabolic disease. J Clin Invest 2017;127:1-4. doi:10.1172/JCI92035.

7. Mraz M, Haluzik M. The role of adipose tissue immune cells in obesity and low-grade inflammation. J Endocrinol 2014;222:R113-27. doi:10.1530/JOE-14-0283.

8. Ding C, Parameswaran V, Cicuttini F, et al. Association between leptin, body composition, sex and knee cartilage morphology in older adults: The Tasmanian older adult cohort (TASOAC) study. Ann Rheum Dis 2008;67:1256-61. doi:10.1136/ard.2007.082651.

9. Hawker GA, Stewart L, French MR, et al. Understanding the pain experience in hip and knee osteoarthritis - an OARSI/OMERACT initiative. Osteoarthritis Cartilage 2008;16:415-22. doi:10.1016/j.joca.2007.12.017. 
10. Sowers MR, Karvonen-Gutierrez CA. The evolving role of obesity in knee osteoarthritis. Curr Opin Rheumatol 2010;22:533-7. doi:10.1097/BOR.0b013e32833b4682.

11. Tian Y, Wang S, Ma Y, Lim G, Kim H, Mao J. Leptin enhances NMDA-induced spinal excitation in rats: A functional link between adipocytokine and neuropathic pain. Pain 2011;152:1263-71. doi:10.1016/j.pain.2011.01.054.

12. Arthritis: National Statistics. 2017. (Accessed 15 NOV 2017, at https://www.cdc.gov/arthritis/data_statistics/national-statistics.html.)

13. Theis KA, Roblin D, Helmick CG, Luo R. Prevalence and causes of work disability among working-age U.S. adults, 2011-2013, NHIS. Disabil Health J 2015;11:108-15. doi:10.1016/j.dhjo.2017.04.010.

14. Arthritis: Cost Statistics. Department of Health and Human Services, 2017. (Accessed 15 NOV 2017, 2017, at https://www.cdc.gov/arthritis/data_statistics/cost.htm.)

15. Barbour KE, Helmick CG, Boring M, Brady TJ. Vital Signs: Prevalence of DoctorDiagnosed Arthritis and Arthritis-Attributable Activity Limitation — United States, 2013-2015. MMWR Morbidity and Mortality Weekly Report 2017;66:246-53. doi:10.15585/mmwr.mm6609e1.

16. Xia B, Di C, Zhang J, Hu S, Jin H, Tong P. Osteoarthritis Pathogenesis: A Review of Molecular Mechanisms. Calcif Tissue Int 2014;95:495-505. doi:10.1007/s00223-014-9917-9. 17. Murphy L, Schwartz TA, Helmick CG, et al. Lifetime risk of symptomatic knee osteoarthritis. Arthritis Care Res 2008;59:1207-13. doi:10.1002/art.24021.

18. van der Meijden OA, Gaskill TR, Millett PJ. Glenohumeral Joint Preservation: A Review of Management Options for Young, Active Patients with Osteoarthritis. Adv Orthop 2012;2012:1-9. doi:10.1155/2012/160923. 
19. Ogden CL, Carroll MD, Fryar CD, Flegal KM. Prevalence of Obesity Among Adults and Youth: United States, 2011-2014. NCHS data brief 2015:1-8. doi:10.1017/S1368980017000088.

20. Finkelstein EA, Trogdon JG, Cohen JW, Dietz W. Annual medical spending attributable to obesity: Payer-and service-specific estimates. Health Aff (Millwood) 2009;28. doi:10.1377/hlthaff.28.5.w822.

21. Hotamisligil GS. Inflammation and metabolic disorders. Nature 2006;444:860-7. doi:10.1038/nature05485.

22. Shi H, Kokoeva MV, Inouye K, Tzameli I, Yin H, Flier JS. TLR4 links innate immunity and fatty acid - induced insulin resistance. J Clin Invest 2006;116:3015-25. doi:10.1172/JCI28898.TLRs.

23. Lee YS, Kim JW, Osborne O, et al. Increased adipocyte O2 consumption triggers HIF1??, causing inflammation and insulin resistance in obesity. Cell 2014;157:1339-52. doi:10.1016/j.cell.2014.05.012.

24. Neels JG, Olefsky JM. Inflamed fat: What starts the fire? J Clin Invest 2006;116:13-35. doi:10.1172/JCI27280.

25. Yu R. Immune-Signaling Molecules and Obesity-Induced Inflammation. J Nutr Sci Vitaminol (Tokyo) 2015;61 Suppl:S131-2. doi:10.3177/jnsv.61.S131.

26. Riddle DL, Stratford PW. Body weight changes and corresponding changes in pain and function in persons with symptomatic knee osteoarthritis: a cohort study. Arthritis Care Res (Hoboken) 2013;65:15-22. doi:10.1002/acr.21692.

27. Runhaar J, Koes BW, Clockaerts S, Bierma-Zeinstra SMA. A systematic review on changed biomechanics of lower extremities in obese individuals: A possible role in development of osteoarthritis. Obes Rev 2011;12:1071-82. doi:10.1111/j.1467-789X.2011.00916.x. 
28. Gandhi R, Perruccio AV, Rizek R, Dessouki O, Evans HMK, Mahomed NN. Obesityrelated adipokines predict patient-reported shoulder pain. Obesity Facts 2013;6:536-41. doi:10.1159/000357230.

29. Hawellek T, Hubert J, Hischke S, et al. Articular cartilage calcification of the humeral head is highly prevalent and associated with osteoarthritis in the general population. J Orthop Res 2016;34:1984-90. doi:10.1002/jor.23227.

30. Sankaye P, Ostlere S. Arthritis at the shoulder joint. Semin Musculoskelet Radiol 2015;19:307-18. doi:10.1055/s-0035-1549324.

31. Wanner J, Subbaiah R, Skomorovska-Prokvolit Y, et al. Proteomic profiling and functional characterization of early and late shoulder osteoarthritis. Arthritis Res Ther 2013;15:R180-R. doi:10.1186/ar4369.

32. Dumond H, Presle N, Terlain B, et al. Evidence for a Key Role of Leptin in Osteoarthritis. Arthritis Rheum 2003;48:3118-29. doi:10.1002/art.11303.

33. Stannus O, Jones G, Cicuttini F, et al. Circulating levels of IL-6 and TNF- $\alpha$ are associated with knee radiographic osteoarthritis and knee cartilage loss in older adults. Osteoarthritis Cartilage 2010;18:1441-7. doi:10.1016/j.joca.2010.08.016.

34. Cho HJ, Morey V, Kang JY, Kim KW, Kim TK. Prevalence and Risk Factors of Spine, Shoulder, Hand, Hip, and Knee Osteoarthritis in Community-dwelling Koreans Older Than Age 65 Years. Clin Orthop Relat Res 2015;473:3307-14. doi:10.1007/s11999-015-4450-3.

35. Gandhi R, Takahashi M, Rizek R, Dessouki O, Mahomed NN. Obesity-related adipokines and shoulder osteoarthritis (letter). J Rheumatol 2012;39:2046-8. doi:10.3899/jrheum.111339. 
36. Charlson ME, Pompei P, Ales KL, MacKenzie CR. A new method of classifying prognostic comorbidity in longitudinal studies: development and validation. J Chronic Dis 1987;40:373-83. doi:

37. Gandhi R, Kapoor M, Mahomed NN, Perruccio AV. A comparison of obesity related adipokine concentrations in knee and shoulder osteoarthritis patients. Obes Res Clin Pract 2015;9:420-3. doi:10.1016/j.orcp.2015.02.003.

38. Simopoulou T, Malizos KN, Iliopoulos D, et al. Differential expression of leptin and leptin's receptor isoform (Ob-Rb) mRNA between advanced and minimally affected osteoarthritic cartilage; effect on cartilage metabolism. Osteoarthritis Cartilage 2007;15:872-83. doi:10.1016/j.joca.2007.01.018.

39. Wluka AE, Lombard CB, Cicuttini FM. Tackling obesity in knee osteoarthritis. Nat Rev Rheumatol 2013;9:225-35. doi:10.1038/nrrheum.2012.224.

40. Gandhi R, Takahashi M, Virtanen C, Syed K, Davey JR, Mahomed NN. Microarray analysis of the infrapatellar fat pad in knee osteoarthritis: relationship with joint inflammation. $\mathrm{J}$ Rheumatol 2011;38:1966-72. doi:10.3899/jrheum.101302.

41. Presle N, Pottie P, Dumond H, et al. Differential distribution of adipokines between serum and synovial fluid in patients with osteoarthritis. Contribution of joint tissues to their articular production. Osteoarthritis Cartilage 2006;14:690-5. doi:10.1016/j.joca.2006.01.009.

42. Abou-Raya S, Abou-Raya A Fau - Helmii M, Helmii M. Duloxetine for the management of pain in older adults with knee osteoarthritis: randomised placebo-controlled trial. Age Aging 2012;41:646-52. doi:

43. Chappell AS, Desaiah D, Liu-Seifert H, et al. A Double-blind, Randomized, Placebocontrolled Study of the Efficacy and Safety of Duloxetine for the Treatment of Chronic Pain Due 
to Osteoarthritis of the Knee. Pain Practice 2011;11:33-41. doi:10.1111/j.15332500.2010.00401.x.

44. Chappell AS, Ossanna MJ, Liu-Seifert H, et al. Duloxetine, a centrally acting analgesic, in the treatment of patients with osteoarthritis knee pain: A 13-week, randomized, placebocontrolled trial. Pain 2009;146:253-60. doi:10.1016/j.pain.2009.06.024.

45. Sullivan MD, Bentley S, Fan M-Y, Gardner G. A Single-Blind, Placebo Run-in Study of Duloxetine for Activity-Limiting Osteoarthritis Pain. J Pain 2009;10:208-13. doi:

46. Sullivan M, Bentley S, Fan MY, Gardner G. A single-blind placebo run-in study of venlafaxine XR for activity-limiting osteoarthritis pain. Pain Med 2009;10:806-12. doi:10.1111/j.1526-4637.2009.00637.x.

47. Citrome L, Weiss-Citrome A. A systematic review of duloxetine for osteoarthritic pain: What is the number needed to treat, number needed to harm, and likelihood to be helped or harmed? Postgrad Med 2012;124:83-93. doi:10.3810/pgm.2012.01.2521.

48. Vonsy JL, Ghandehari J, Dickenson AH. Differential analgesic effects of morphine and gabapentin on behavioural measures of pain and disability in a model of osteoarthritis pain in rats. Eur J Pain 2009;13:786-93. doi:10.1016/j.ejpain.2008.09.008.

49. Beyreuther B, Callizot N, Stöhr T. Antinociceptive efficacy of lacosamide in the monosodium iodoacetate rat model for osteoarthritis pain. Arthritis Res Ther 2007;9. doi:10.1186/ar2121.

50. Rahman W, Dickenson AH. Antinociceptive effects of lacosamide on spinal neuronal and behavioural measures of pain in a rat model of osteoarthritis. Arthritis Res Ther 2014;16:509-. doi:10.1186/s13075-014-0509-X. 
Table 1: Glenohumeral Osteoarthritis and Arthroplasty Prevalence and Odds Ratios by Body Mass Index Cohort

\begin{tabular}{|c|c|c|c|c|c|c|}
\hline & \multicolumn{6}{|c|}{ Body Mass Index $\left(\mathrm{kg} / \mathrm{m}^{2}\right)$} \\
\hline & $<19$ & $19-24$ & 25-29 & $30-34$ & $35-39$ & $>39$ \\
\hline Cohort count (\#) & 99479 & 99479 & 99479 & 99479 & 99479 & 99479 \\
\hline Mean CCI (SD) & $3.31(3.58)$ & $2.40(2.98)$ & $2.46(2.93)$ & $2.73(3.02)$ & $3.03(3.09)$ & $3.44(3.24)$ \\
\hline GH OA (\%) & 3119 (3.14) & $3740(3.76)$ & $4380(4.40)$ & $5082(5.11)$ & $5648(5.68)$ & $5834(5.86)$ \\
\hline Odds Ratio & REF & $1.21^{*}$ & $1.42 *$ & 1.66* & $1.86^{*}$ & $1.92 *$ \\
\hline (95\%CI) & REF & $(1.15-1.27)$ & $(1.36-1.49)$ & $(1.59-1.74)$ & $(1.78-1.94)$ & $(1.84-2.01)$ \\
\hline GH Arthro. (\%) & $219(7.02)$ & $256(6.84)$ & $329(7.51)$ & $418(8.23)$ & $590(10.45)$ & $600(10.28)$ \\
\hline Odds Ratio & REF & 0.97 & 1.08 & 1.19* & $1.54 *$ & $1.52 *$ \\
\hline (95\%CI) & REF & $(0.81-1.17)$ & $(0.90-1.28)$ & $(1.00-1.41)$ & $(1.31-1.82)$ & $(1.29-1.78)$ \\
\hline
\end{tabular}

BMI= Body Mass Index; CCI=Charlson Comorbidity Index; SD=standard deviation; GH OA=number of patients in cohort with glenohumeral osteoarthritis (\% of cohort with GH OA); 95\%CI= $95 \%$ confidence interval; GH Arthro. = number of patients who underwent glenohumeral arthroplasty (\% of patients with GH OA in the cohort who also underwent arthroplasty); REF $=$ referent cohort for odds ratio calculations; * indicates significance at $\alpha=0.05$ 
Appendix A: The efficacy of anti-neuropathic pain medications in managing osteoarthritis pain: A systematic review 


\section{Introduction:}

For years, the management of osteoarthritis (OA) pain has been targeted towards the nociceptive pain component of this condition. It was not until recently that the neuropathic pain aspect of this degenerative disease ${ }^{1}$ was acknowledged by the Food and Drug Administration, with the approval of duloxetine ${ }^{2}$. As one of many medications that treated neuropathic pain, duloxetine represented one of the few other ways that clinicians were able to conservatively treat the pain of OA until additional research into the efficacy of other anti-neuropathic pain medications was conducted. While there remains a dearth of literature on this topic, some studies - both animal and clinical - have been published in recent years that offer support for the use of these medications to dampen this pathway and assist patients in pain control. The purpose of this systematic review is to evaluate the recent body of literature on the pain management in OA using medications with presumed anti-neuropathic pain mechanisms.

\section{Methods:}

The Preferred Reporting Items for Systematic reviews and Meta-Analyses (PRISMA) ${ }^{3}$ guidelines were used for this systematic review. This protocol was not registered with any database.

\section{Eligibility criteria:}

Full eligibility criteria are summarized in Table 1. Studies were considered eligible if they: presented original data on pain reduction in OA using an anti-neuropathic pain medication. Only English-language articles that were published since the year 2000 were included. Both animal and clinical studies were considered eligible. Anti-neuropathic pain medications were 
defined as any anti-epileptic or anti-depressant medications that may also have a theoretical benefit in reducing OA pain as suggested by the literature. No direct comparator was necessary; uncontrolled studies and both placebo-controlled and non-placebo, comparative studies were included. Pain reduction was the primary outcome of interest, defined as the presence or absence of statistically significant decreased pain, by any measure, in the experimental, anti-neuropathic pain medication group, relative to that group’s baseline and/or the placebo group.

Information sources and search strategy:

MEDLINE was queried using the PubMed search engine to identify all studies that meet inclusion criteria. Search terms included: “arthritis,” “osteoarthritis,” “neuropathic,” “pain,” “medication,” “gabapentin,” “carbamazepine,” “lamotrigine,” “phenytoin,” “venlafaxine,” “paroxetine,” “citalopram,” “bupropion,” “amitriptyline,” “nortriptyline,” “desipramine,” “duloxetine,” and affiliated terms using the PubMed MeSH tool. This search was conducted on May 23, 2018 and includes all results published since 2000. Reference lists of included articles were also screened to identify any relevant articles not found in the database search.

\section{Study selection and data extraction:}

Titles and abstracts from all sources were screened for eligibility by K.W.; full-text articles of abstracts marked as potentially relevant were screened against the same eligibility criteria. All screening was conducted using the online systematic review tool, Covidence (https://www.covidence.org).

Relevant data were abstracted from all included studies in terms of study characteristics, enrolled populations, interventions, comparators, and outcomes. Due to the wide variability in 
tools used to measure pain reduction across these animal and clinical studies, data on this variable were extracted as dichotomous for both pain reduction relative to baseline and placebo. When possible, multiple timepoints were captured. Significance for the pain reduction measures was also extracted, as were any adverse effects of the anti-neuropathic pain medication noted in the results of these studies.

\section{Risk of bias and analysis:}

We used the Cochrane tool ${ }^{4}$ for assessing risk of bias in randomized controlled trials (RCT) and the ROBINS-I tool ${ }^{5}$ for non-randomized studies. Given the expected small volume of literature on this topic, all studies that otherwise met eligibility criteria were included, regardless of their overall risk of bias. Results are summarized qualitatively. Due to the small and heterogenous body of literature meta-analysis was not appropriate.

\section{Results:}

Study selection and characteristics:

Following the removal of duplicates, 464 studies underwent title and abstract screening for eligibility and 56 of these were assessed during full-text review. Of these studies, the most common reasons for exclusion was the study of non-OA patients or animals, followed using nonpain reduction outcomes (Figure 1). Nine studies ${ }^{6-14}$ were included in our final analysis (Table 2). Four of the articles were RCTs ${ }^{6-9}$ and four articles were also animal studies ${ }^{7,10,11,14}$. The most commonly studied medication was duloxetine, which was studied in five of the nine articles $^{6,8-10,13}$. The overall bias of studies trended towards being low in all studies and is elaborated in Tables 3 and 4. 


\section{Outcomes data:}

Duloxetine studied in five studies and was shown to be efficacious in reducing OA pain in humans and rats both from baseline and when compared to placebo ${ }^{6,8-10,13}$. In humans, the dose ranged from $60 \mathrm{mg}$ daily ${ }^{6}$ up to $120 \mathrm{mg}$ daily ${ }^{8,9}$ and data were frequently captured over 12 weeks to 16 weeks of follow-up ${ }^{6,13}$. The other serotonin-norepinephrine reuptake inhibitor, venlafaxine, was also studied in humans and was similarly found to reduce patient's pain at the final, 12 week time point at doses up to $225 \mathrm{mg}$ daily ${ }^{12}$. The final, and most recent, study of either of these two drugs was published in 2014 and was an animal study documenting significant pain reduction when duloxetine was compared to placebo and when the final timepoint was compared to baseline for pain at rest alone; comparing pain during locomotion between the baseline and final timepoints did not yield significant results ${ }^{10}$.

Two studies administered lacosamide to rats to determine its effect on controlling OA pain $^{7,11}$. In one study, a reduction in pain from baseline was documented at the final, 2 weeks post-OA induction, timepoint ${ }^{11}$ and in the other, only results comparing this drug to placebo were reported $^{7}$. These investigators found that lacosamide, when administered on the days they evaluated pain (days 3, 7 and 14 post-OA induction) performed significantly better than placebo on days 3 and 7, but not day 14. Gabapentin was studied in only one included article, a singlecohort study. This drug's subcutaneous administration to rats was shown to significantly reduce their OA pain after approximately two weeks ${ }^{14}$.

\section{Discussion:}


Consistent evidence from the literature supports the use of duloxetine in the human population to treat OA pain. Indeed, multiple randomized controlled trials in humans have documented this effect ${ }^{6,8,9}$. Despite its ability to help patients control their pain, duloxetine has potential adverse effects. Studies have documented both significantly more adverse events in the duloxetine group than the placebo group ${ }^{6}$ and increased rates of study discontinuation in a similar fashion ${ }^{8}$. Further research is needed to assess the comparative efficacy, harms and tolerability of duloxetine against other conservatively used medications.

Given the aforementioned increased rate of glenohumeral OA in patients at higher BMI levels and the proposed susceptibility to neuropathic pain in this same population, there may be increased benefit to prescribing a medication such as duloxetine specifically in these patients. Additional studies will need to be conducted to determine if the use of duloxetine, with otherwise proven, general efficacy in OA, should be considered first-line conservative therapy in the obese population.

The research on venlafaxine, lacosamide and gabapentin in OA remains sparse ${ }^{7,11,12,14}$. More conclusive evidence is needed to determine whether these medications are routinely used in are effective in the general OA population, and also subpopulations of patients with high BMI. The current studies in this domain are promising and well-conducted, albeit largely not yet in the clinical trial phase. Further research into the mechanisms behind obesity-induced neuropathic pain sensitivity will be helpful in determining which of these drugs can provide the greatest benefit in OA patients. 


\section{Conclusions:}

Duloxetine represents a valid approach to the management of OA pain in the general population. There is insufficient evidence regarding the use of venlafaxine, lacosamide (due to few studies assessing each medication), however existing studies show promising preliminary results. No studies assessing these medications were conducted in the obese population (or report on subpopulations defined by BMI); further research should assess this population specifically due to the potential susceptibility to neuropathic pain in those with high BMI. As additional information is uncovered about the mechanisms behind neuropathic pain sensitivity in the obese population, a more personalized approach to managing OA pain in these patients may be developed. 
Appendix A Table 2. Study Eligibility Criteria

\begin{tabular}{|c|c|c|}
\hline PICOTSS & Inclusion Criteria & Exclusion Criteria \\
\hline Populations & $\begin{array}{l}\text { Patients or animals with } \\
\text { primary osteoarthritis }\end{array}$ & $\begin{array}{l}\text { Rheumatoid or other } \\
\text { inflammatory arthritis }\end{array}$ \\
\hline Interventions & $\begin{array}{l}\text { Any anti-neuropathic pain } \\
\text { medication }\end{array}$ & All other medications \\
\hline Comparators & No restrictions & Not applicable \\
\hline Outcomes & $\begin{array}{l}\text { Pain reduction from baseline } \\
\text { or when compared to placebo }\end{array}$ & Non-pain related measures \\
\hline Timing & Published after 2000 & Published prior to 2000 \\
\hline Settings & No restrictions & Not applicable \\
\hline Study Design & $\begin{array}{l}\text { Reporting original data; RCT, } \\
\text { cohort study (with or without } \\
\text { a control group), case- } \\
\text { control, cross-sectional, case } \\
\text { study, case series, animal } \\
\text { study }\end{array}$ & $\begin{array}{l}\text { Non-original data; editorial, } \\
\text { letter, comment, review, } \\
\text { meta-analysis }\end{array}$ \\
\hline
\end{tabular}


Appendix A Figure 1. PRISMA Flow Diagram

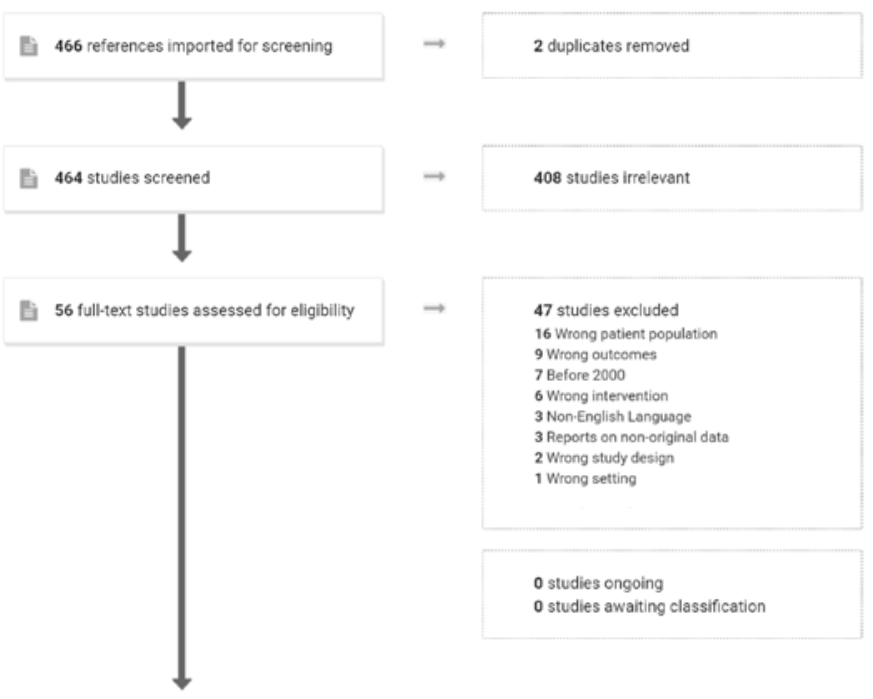

9 studies included 
Appendix A Table 3. Included Study Characteristics and Results

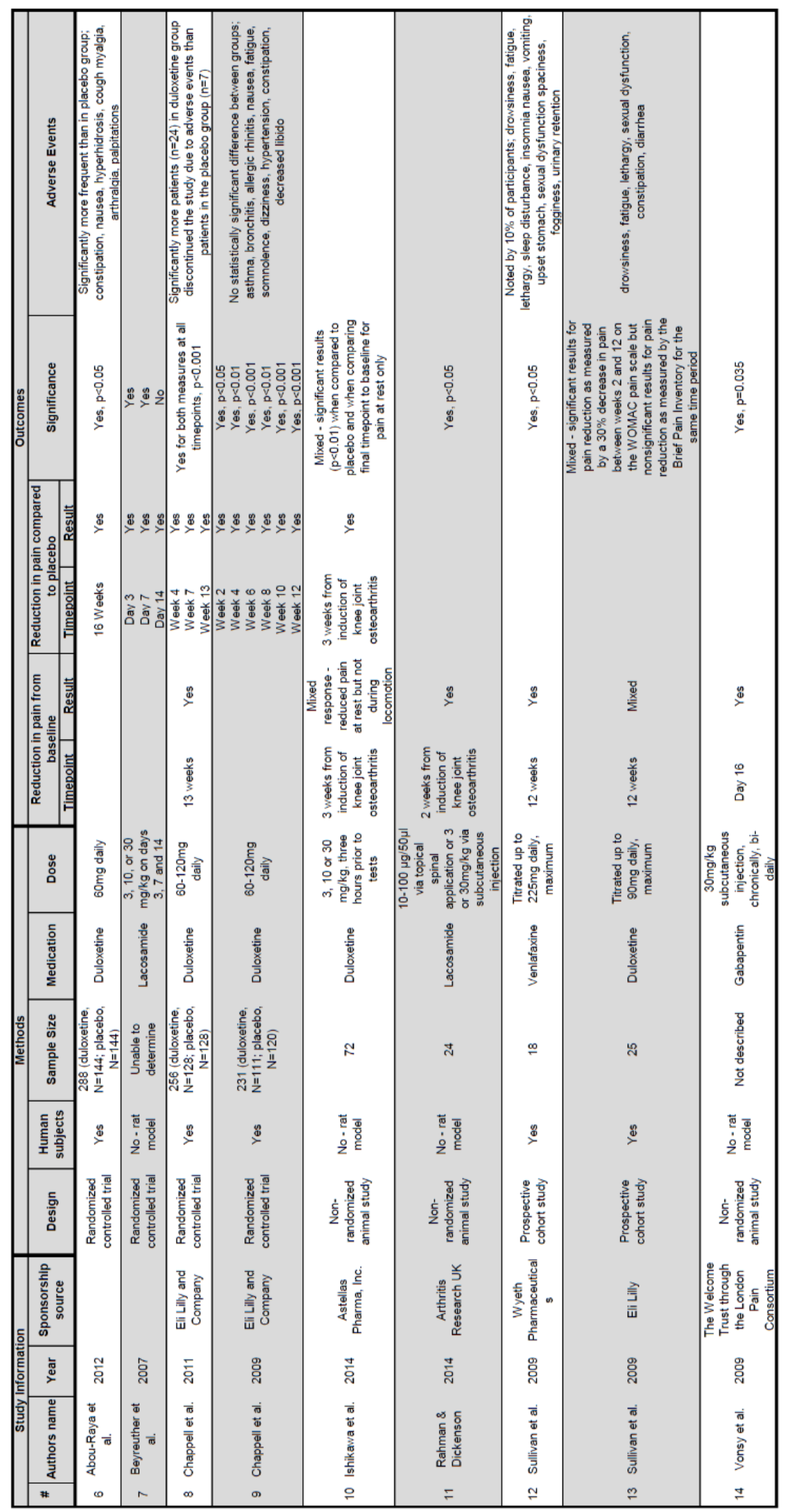


Appendix A Table 4. Risk of Bias Assessment for Included Randomized Controlled Trials

\begin{tabular}{|c|c|c|c|c|c|c|c|c|c|}
\hline \multicolumn{3}{|c|}{ Study Information } & \multicolumn{7}{|c|}{ Cochrane Tool } \\
\hline$\#$ & Author name & Year & $\begin{array}{c}\text { Sequence } \\
\text { generation }\end{array}$ & $\begin{array}{l}\text { Allocation } \\
\text { concealment }\end{array}$ & $\begin{array}{c}\text { Blinding of } \\
\text { participants and } \\
\text { personnel for all } \\
\text { outcomes }\end{array}$ & $\begin{array}{c}\text { Blinding of } \\
\text { outcome } \\
\text { assessors for all } \\
\text { outcomes }\end{array}$ & $\begin{array}{c}\text { Incomplete } \\
\text { outcome data } \\
\text { for all } \\
\text { outcomes }\end{array}$ & $\begin{array}{l}\text { Selective } \\
\text { outcome } \\
\text { reporting }\end{array}$ & $\begin{array}{c}\text { Other } \\
\text { sources of } \\
\text { bias }\end{array}$ \\
\hline 6 & $\begin{array}{l}\text { Abou-Raya } \\
\text { et al. }\end{array}$ & 2012 & high & high & high & low & low & low & low \\
\hline 8 & $\begin{array}{l}\text { Chappell et } \\
\text { al. }\end{array}$ & 2011 & low & low & low & low & low & low & low \\
\hline 9 & $\begin{array}{l}\text { Chappell et } \\
\text { al. }\end{array}$ & 2009 & low & low & low & unclear & low & low & low \\
\hline 11 & $\begin{array}{l}\text { Rahman \& } \\
\text { Dickenson }\end{array}$ & 2014 & low & low & low & low & low & low & low \\
\hline
\end{tabular}

Appendix A Table 5. Risk of Bias Assessment for Included Non-Randomized Controlled Trials

\begin{tabular}{|c|c|c|c|c|c|c|c|c|c|c|}
\hline \multirow[b]{2}{*}{$\#$} & \multirow[b]{2}{*}{$\begin{array}{l}\text { Author } \\
\text { name }\end{array}$} & \multirow[b]{2}{*}{ Year } & \multicolumn{2}{|c|}{ Pre-intervention domain } & \multirow{2}{*}{\begin{tabular}{|c|}
$\begin{array}{c}\text { At-intervention } \\
\text { domain }\end{array}$ \\
Bias in \\
classification of \\
interventions
\end{tabular}} & \multicolumn{4}{|c|}{ Post-intervention domain } & \multirow[b]{2}{*}{$\underset{\text { judgment }}{\text { Final }}$} \\
\hline & & & $\begin{array}{l}\text { Bias due to } \\
\text { confounding }\end{array}$ & $\begin{array}{c}\text { Bias in } \\
\text { selection } \\
\text { of participants } \\
\text { into the study }\end{array}$ & & $\begin{array}{c}\text { Bias due to } \\
\text { deviations } \\
\text { from } \\
\text { intended } \\
\text { interventions }\end{array}$ & $\begin{array}{c}\text { Bias due to } \\
\text { missing data }\end{array}$ & $\begin{array}{c}\text { Bias in } \\
\text { measurement } \\
\text { of outcomes }\end{array}$ & $\begin{array}{l}\text { Bias in } \\
\text { selection } \\
\text { of the } \\
\text { reported } \\
\text { result }\end{array}$ & \\
\hline 7 & $\begin{array}{l}\text { Beyreuther } \\
\text { et al. }\end{array}$ & 2007 & low & low & low & low & low & low & low & low \\
\hline 10 & $\begin{array}{c}\text { Ishikawa et } \\
\text { al. }\end{array}$ & 2014 & low & low & low & low & low & low & low & low \\
\hline 12 & $\begin{array}{c}\text { Sullivan et } \\
\text { al. }\end{array}$ & 2009 & low & low & low & low & low & low & low & low \\
\hline 13 & $\begin{array}{c}\text { Sullivan et } \\
\text { al. }\end{array}$ & 2009 & low & low & low & low & low & low & low & low \\
\hline 14 & Vonsy et al. & 2009 & low & low & low & low & low & low & low & low \\
\hline
\end{tabular}




\section{Appendix A References}

1. Gandhi R, Perruccio AV, Rizek R, Dessouki O, Evans HMK, Mahomed NN. Obesityrelated adipokines predict patient-reported shoulder pain. Obesity Facts. 2013;6(6):536-41.

2. Citrome L, Weiss-Citrome A. A systematic review of duloxetine for osteoarthritic pain: What is the number needed to treat, number needed to harm, and likelihood to be helped or harmed? Postgraduate Medicine. 2012;124(1):83-93.

3. Moher D, Liberati A, Tetzlaff J, Altman DG, Group P. Preferred reporting items for systematic reviews and meta-analyses: the PRISMA statement. J Clin Epidemiol. 2009;62(10):1006-12.

4. Higgins JP, Altman DG, Gotzsche PC, Juni P, Moher D, Oxman AD, et al. The Cochrane Collaboration's tool for assessing risk of bias in randomised trials. BMJ. 2011;343:d5928.

5. Sterne JA, Hernan MA, Reeves BC, Savovic J, Berkman ND, Viswanathan M, et al. ROBINS-I: a tool for assessing risk of bias in non-randomised studies of interventions. BMJ. 2016;355:i4919.

6. Abou-Raya S, Abou-Raya A Fau - Helmii M, Helmii M. Duloxetine for the management of pain in older adults with knee osteoarthritis: randomised placebo-controlled trial. Age Aging. 2012;41(5):646-52.

7. Beyreuther B, Callizot N, Stöhr T. Antinociceptive efficacy of lacosamide in the monosodium iodoacetate rat model for osteoarthritis pain. Arthritis Research \& Therapy. 2007;9. 8. Chappell AS, Desaiah D, Liu-Seifert H, Zhang S, Skljarevski V, Belenkov Y, et al. A Double-blind, Randomized, Placebo-controlled Study of the Efficacy and Safety of Duloxetine for the Treatment of Chronic Pain Due to Osteoarthritis of the Knee. Pain Practice. 2011;11(1):33-41. 
9. Chappell AS, Ossanna MJ, Liu-Seifert H, Iyengar S, Skljarevski V, Li LC, et al.

Duloxetine, a centrally acting analgesic, in the treatment of patients with osteoarthritis knee pain:

A 13-week, randomized, placebo-controlled trial. Pain. 2009;146(3):253-60.

10. Ishikawa G, Nagakura Y, Takeshita N, Shimizu Y. Efficacy of drugs with different mechanisms of action in relieving spontaneous pain at rest and during movement in a rat model of osteoarthritis. Eur J Pharmacol. 2014;738:111-7.

11. Rahman W, Dickenson AH. Antinociceptive effects of lacosamide on spinal neuronal and behavioural measures of pain in a rat model of osteoarthritis. Arthritis research \& therapy. 2014;16(6):509-.

12. Sullivan M, Bentley S, Fan MY, Gardner G. A single-blind placebo run-in study of venlafaxine XR for activity-limiting osteoarthritis pain. Pain Medicine. 2009;10(5):806-12.

13. Sullivan MD, Bentley S, Fan M-Y, Gardner G. A Single-Blind, Placebo Run-in Study of Duloxetine for Activity-Limiting Osteoarthritis Pain. J Pain. 2009;10(2):208-13.

14. Vonsy JL, Ghandehari J, Dickenson AH. Differential analgesic effects of morphine and gabapentin on behavioural measures of pain and disability in a model of osteoarthritis pain in rats. Eur J Pain. 2009;13(8):786-93. 